\title{
Estimativas dos requisitos nutricionais e utilização do modelo Small Ruminant Nutrition System para ovinos deslanados em condições semiáridas
}

\section{Estimates of nutritional requirements and use of Small Ruminant Nutrition System model for hair sheep in semiarid conditions}

\author{
Alessandra Pinto de Oliveira ${ }^{1}$; Elzânia Sales Pereira ${ }^{2}$; Andréa Pereira Pinto ${ }^{3 *}$; \\ Aderbal Marcos de Azevêdo Silva ${ }^{4}$; Maria Socorro de Souza Carneiro ${ }^{3}$; \\ Ivone Yurika Mizubuti ${ }^{5}$; Edson Luis de Azambuja Ribeiro ${ }^{5}$; \\ Ana Cláudia Nascimento Campos ${ }^{3}$; Carla Renata Figueiredo Gadelha ${ }^{3}$
}

\begin{abstract}
Resumo
O objetivo foi determinar as eficiências de utilização da energia metabolizável para mantença $(\mathrm{km})$ e ganho de peso (kf), as exigências dietéticas de nutrientes digestíveis totais (NDT) e proteína metabolizável (PM), assim como, avaliar o modelo Small Ruminant Nutrition System (SRNS) para predizer o consumo de matéria seca (CMS) e o ganho médio diário (GMD) de cordeiros Santa Inês, alimentados com dietas contendo diferentes níveis de energia metabolizável (EM). Foram utilizados 35 cordeiros, não castrados, com peso corporal (PC) médio inicial de 14,77 $\pm 1,26 \mathrm{~kg}$ e idade aproximada de dois meses. Inicialmente cinco animais foram abatidos para servirem como referência para as estimativas do peso de corpo vazio (PCVZ) e composição corporal inicial dos 30 animais remanescentes, que foram distribuídos em delineamento em blocos casualizados com cinco tratamentos $(1,13 ; 1,40 ; 1,73 ; 2,22$ e $2,60 \mathrm{Mcal} / \mathrm{kg} \mathrm{MS})$ e seis repetições. O requerimento de EM para mantença foi de $78,53 \mathrm{kcal} / \mathrm{kg} \mathrm{PCVZ}{ }^{0,75} / \mathrm{dia}$, com uma eficiência de utilização de $66 \%$. O valor médio da eficiência de utilização da EM para ganho de peso foi de $48 \%$. As exigências dietéticas de NDT e PM aumentaram com o acréscimo no PC e no GMD dos animais. O modelo SRNS subestimou o CMS e o GMD dos animais em $6,2 \%$ e $24,6 \%$, respectivamente. Conclui-se que os valores de $\mathrm{km}$ e kf são consistentes com aqueles observados em diversos estudos com cordeiros criados nos trópicos. As exigências dietéticas de NDT e PM de cordeiros Santa Inês para diferentes PC e GMD são, aproximadamente, de $42 \%$ e $24 \%$, respectivamente, inferiores àquelas sugeridas pelo sistema americano de avaliação de alimentos e requerimentos nutricionais de pequenos ruminantes. O modelo SRNS foi sensível para predizer o CMS em cordeiros Santa Inês, entretanto, para variável GMD, mais estudos são necessários, uma vez que, o modelo subestimou a resposta dos animais neste estudo.

Palavras-chave: Consumo, metabolizabilidade, ovinos, proteína metabolizável
\end{abstract}

\footnotetext{
${ }^{1}$ Discente de Doutorado do Programa de Doutorado Integrado em Zootecnia da Universidade Federal do Ceará, UFC, Fortaleza, CE. E-mail: alessandra_zoo@yahoo.com.br

${ }^{2}$ Prof $^{a}$ Dr $^{a}$ do Dept ${ }^{\circ}$ de Zootecnia, UFC, Fortaleza, CE. Bolsista de Produtividade do CNPq. E-mail: elzania@hotmail.com

${ }^{3}$ Prof $^{\text {as }}$ Dr $^{\text {as }}$ do Dept ${ }^{\circ}$ de Zootecnia, UFC, Fortaleza, CE. E-mail: deiapp@hotmail.com; msocorro@ufc.br; anccampos11@gmail. com; crgadelha@yahoo.com.br

${ }^{4}$ Prof. Dr. da Unidade Acadêmica de Medicina Veterinária. Universidade Federal de Campina Grande, UFCG, Patos, PB. Bolsista de Produtividade do CNPq. E-mail: aderbal@pq.cnpq.br

${ }^{5}$ Profs. Drs. do Dept $^{\circ}$ de Zootecnia, Universidade Estadual de Londrina, UEL. Bolsista de Produtividade do CNPq. E-mail: mizubuti@uel.br; elar@uel.br

* Autor para correspondência
} 


\begin{abstract}
The objective was to determine the efficiency of utilization of metabolizable energy for maintenance $(\mathrm{km})$ and weight gain $(\mathrm{kf})$, the dietary requirements of total digestible nutrients (TDN) and metabolizable protein (MP), as well as, evaluate the Small Ruminant Nutrition System (SRNS) model to predict the dry matter intake (DMI) and the average daily gain (ADG) of Santa Ines lambs, fed diets containing different levels of metabolizable energy (ME). Thirty five lambs, non-castrated, with initial body weight (BW) of $14.77 \pm 1.26 \mathrm{~kg}$ at approximate two months old, were used. At the beginning of the experiment, five animals were slaughtered to serve as reference for the estimative of empty body weight (EBW) and initial body composition of the 30 remaining animals, which were distributed in randomized block design with five treatments $(1.13 ; 1.40 ; 1.73 ; 2.22$ and $2.60 \mathrm{Mcal} / \mathrm{kg} \mathrm{DM})$, and six repetitions. The requirement of metabolizable energy for maintenance was $78.53 \mathrm{kcal} / \mathrm{kg} \mathrm{EBW}$ W $^{0,75} /$ day, with a utilization efficiency of $66 \%$. The average value of efficiency of metabolizable energy utilization for weight gain was $48 \%$. The dietary requirements of TDN and MP increased with the increase in BW and ADG of the animals. The SRNS model underestimated the DMI and ADG of the animals in $6.2 \%$ and $24.6 \%$, respectively. Concludes that the values of $\mathrm{km}$ and $\mathrm{kf}$ are consistent with those observed in several studies with lambs created in the tropics. The dietary requirements of TDN and MP of Santa Ines lambs for different BW and ADG are, approximately, $42 \%$ and $24 \%$, respectively, lower than those suggested by the american system of evaluation of food and nutrient requirements of small ruminants. The SRNS model was sensitive to predict the DMI in Santa Ines lambs, however, for variable ADG, more studies are needed, since the model underestimated the response of the animals of this study.
\end{abstract}

Key words: Consumption, metabolizable protein, metabolizability, sheep

\section{Introdução}

Para a formulação de dietas adequadas é necessário conhecer o valor nutricional dos alimentos e as exigências nutricionais dos animais. No entanto, em virtude das poucas informações sobre os requerimentos nutricionais de ovinos criados em condições brasileiras, os cálculos de rações têm sido baseados em recomendações de sistemas internacionais, dentre os quais, os mais utilizados no Brasil para pequenos ruminantes são: o sistema americano (NRC - National Research Council), o britânico (AFRC - Agricultural and Food Research Council), o francês (INRA - Institut National de la Recherche Agronomique) e o australiano (CSIRO Commonwealth Scientific and Industrial Research Organization), cuja genética dos animais e condições ambientais distinguem daquelas encontradas no Brasil (CARVALHO; PIRES; SILVA, 2000; OLIVEIRA et al., 2004; GONZAGA NETO et al., 2005; RESENDE et al., 2008, REGADAS FILHO et al., 2011). Diversos fatores podem influenciar os requerimentos nutricionais, como: a espécie, a raça, o sexo, a idade, o peso corporal, as condições ambientais, as condições fisiológicas (crescimento, gestação ou lactação) e a composição corporal. Desse modo, a adoção de dados preconizados pelos sistemas internacionais de avaliação de alimentos e requerimentos nutricionais pode ocasionar aumento dos custos com alimentação, desperdício de nutrientes, baixa produtividade, menor desempenho animal ou ainda distúrbios metabólicos face ao excesso ou deficiência de nutrientes.

O uso de modelos mecanicistas para estimar o valor biológico dos alimentos e de avaliação das exigências nutricionais de animais tem sido utilizado nos últimos anos (TEDESCHI; CANNAS; FOX, 2008), entretanto, as predições são calculadas a partir dos dados obtidos sob condições sistematicamente diferentes das condições brasileiras (REGADAS FILHO et al., 2011), o que inviabiliza sua utilização para predição do desempenho dos animais criados nessas circunstâncias. A sua aplicação depende da obtenção das informações relativas aos alimentos produzidos nas condições que se deseja obter inferências, observando a resposta produtiva dos animais em determinadas condições dietéticas e validando as predições para outros animais, mantidos em condições semelhantes de 
alimentação. Assim, poderão ser aperfeiçoadas eventuais falhas do sistema, visando adequá-lo às condições predominantes de criação no Brasil.

Diante disso, o objetivo neste estudo foi determinar as eficiências de utilização da energia metabolizável para mantença $(\mathrm{km})$ e ganho de peso (kf), as exigências dietéticas de nutrientes digestíveis totais (NDT) e proteína metabolizável (PM), assim como avaliar o modelo Small Ruminant Nutrition System (SRNS) para predizer o consumo de matéria seca (CMS) e o ganho médio diário (GMD) em cordeiros Santa Inês, alimentados com dietas contendo diferentes níveis de energia metabolizável.

\section{Material e Métodos}

O experimento foi conduzido no Setor de Digestibilidade do Departamento de Zootecnia da Universidade Federal do Ceará, em Fortaleza, Ceará, no período de março a junho de 2011.

Foram utilizados 35 cordeiros da raça Santa Inês, não castrados, com peso corporal (PC) médio inicial de $14,77 \pm 1,26 \mathrm{~kg}$ e idade aproximada de dois meses. Inicialmente, os animais foram identificados com brincos, pesados, vermifugados e distribuídos em baias coletivas providas de cochos, para fornecimento de ração, e água a vontade. Após um período de adaptação de 21 dias, para determinação da composição corporal, de acordo com a metodologia do abate comparativo, cinco animais foram abatidos para servirem como referência para as estimativas do peso de corpo vazio (PCVZ) e composição corporal inicial dos 30 animais remanescentes, os quais foram alocados em baias individuais, providas de cochos e água a vontade. O delineamento experimental utilizado foi blocos casualizados com cinco tratamentos e seis repetições. Os tratamentos consistiram de dietas contendo níveis crescentes de energia metabolizável (EM) $(1,13 ; 1,40 ; 1,73 ; 2,22$ e 2,60 Mcal/kg MS).

As rações experimentais foram formuladas conforme o NRC (2007) a fim de promoverem ganhos diários de $200 \mathrm{~g}$, à exceção do primeiro tratamento, o qual atendia apenas às exigências de mantença. As rações consistiram de feno de capim Tifton-85 (Cynodon sp.) picado e concentrado à base de farelo de soja, grão de milho moído, cloreto de sódio, ureia, calcário, fosfato bicálcico e premix mineral. A composição percentual e bromatológica dos ingredientes e das rações experimentais podem ser visualizadas nas Tabelas 1 e 2 .

Tabela 1. Composição bromatológica dos ingredientes e dos concentrados experimentais em \% na MS.

\begin{tabular}{lcrrrrrr}
\hline \multirow{2}{*}{ Nutrientes } & \multirow{2}{*}{$\begin{array}{c}\text { Feno } \\
\text { de Tifton }\end{array}$} & \multirow{2}{*}{ Milho moído } & \multirow{2}{*}{ Farelo de soja } & \multicolumn{4}{c}{ Concentrados $^{2}$} \\
\cline { 5 - 8 } & 92,00 & 88,61 & 88,10 & 87,64 & 87,96 & 88,22 & 88,85 \\
Matéria seca & 86,38 & 86,27 & 81,22 & 81,47 & 84,67 & 84,35 & 85,38 \\
Matéria orgânica & 9,54 & 10,15 & 50,15 & 42,46 & 26,10 & 20,79 & 18,08 \\
Proteína bruta & 1,85 & 3,67 & 2,35 & 1,37 & 3,18 & 2,78 & 3,40 \\
Extrato etéreo & 5,62 & 2,34 & 6,88 & 6,17 & 3,29 & 3,87 & 3,47 \\
Matéria mineral & 73,45 & 25,06 & 17,67 & 15,24 & 14,70 & 14,72 & 14,71 \\
Fibra em detergente neutro & 66,83 & 22,84 & 15,71 & 13,67 & 13,16 & 13,49 & 12,98 \\
FDNcp & 36,43 & 6,03 & 9,28 & 7,05 & 4,42 & 4,97 & 4,94 \\
Fibra em detergente ácido & 3,41 & 0,95 & 1,64 & 1,08 & 0,79 & 0,90 & 1,01 \\
Lignina & 30,86 & 5,42 & 9,00 & 6,49 & 4,19 & 4,41 & 4,55 \\
Celulose & 37,02 & 19,03 & 8,39 & 8,19 & 10,28 & 9,75 & 9,76 \\
Hemicelulose & 82,99 & 83,84 & 40,62 & 50,00 & 67,43 & 72,56 & 75,05 \\
Carboidratos totais & 16,16 & 61,00 & 24,91 & 41,77 & 56,54 & 61,10 & 62,99 \\
\hline Carboidratos não fibrosos & & & & & & &
\end{tabular}

${ }^{1}$ FDNcp: Fibra em detergente neutro corrigida para cinzas e proteína; ${ }^{2}$ Concentrados formulados para compor as rações experimentais. Fonte: Elaboração dos autores. 
As rações foram fornecidas duas vezes ao dia, às 8:00 e às 16:00 horas, sendo ajustadas diariamente para permitirem, aproximadamente, $20 \%$ de sobras, com base no consumo do dia anterior. O consumo de matéria seca total foi determinado a partir do controle diário da quantidade de ração fornecida e das sobras. Após 21 dias de adaptação às dietas, foram coletadas diariamente as sobras de cada unidade experimental antes da oferta matinal, sendo pesadas, amostradas, acondicionadas em sacos plásticos devidamente identificados e armazenadas em freezer a $-10{ }^{\circ} \mathrm{C}$ para formar, posteriormente, uma amostra composta/animal. As amostras de feno e concentrados, coletadas semanalmente, também foram armazenadas em freezer $\mathrm{a}-10{ }^{\circ} \mathrm{C}$.

Tabela 2. Composição percentual e bromatológica das rações experimentais.

\begin{tabular}{lrrrrr}
\hline \multirow{2}{*}{ Composição Percentual (\%MN) } & \multicolumn{5}{c}{ Concentração de EM (Mcal/ kg de MS) } \\
\cline { 2 - 6 } & 1,13 & 1,40 & 1,73 & 2,22 & 2,60 \\
\hline Feno de Tifton & 100,00 & 80,00 & 60,00 & 40,00 & 20,00 \\
Concentrado & - & 20,00 & 40,00 & 60,00 & 80,00 \\
Milho grão moído & - & 15,87 & 69,45 & 72,46 & 75,61 \\
Farelo de soja & - & 80,65 & 28,53 & 24,88 & 22,59 \\
Ureia & - & 3,00 & 1,25 & 1,12 & 0,51 \\
Calcário & - & - & - & 0,54 & 0,66 \\
Fosfato bicálcico & - & - & - & - & 0,07 \\
Cloreto de sódio & - & 0,40 & 0,70 & 0,93 & 0,50 \\
Premix mineral ${ }^{1}$ & - & 0,08 & 0,07 & 0,07 & 0,06 \\
\hline Composição Bromatológica & & & & & \\
\hline Matéria seca (\%) & 92,00 & 91,13 & 90,38 & 89,73 & 89,48 \\
Matéria mineral (\%MS) & 5,62 & 5,73 & 5,84 & 4,57 & 3,90 \\
Proteína bruta (\%MS) & 9,54 & 16,12 & 16,16 & 16,29 & 16,37 \\
Extrato etéreo (\%MS) & 1,85 & 1,75 & 2,38 & 2,41 & 3,09 \\
Fibra em detergente neutro (\%MS) & 73,45 & 61,81 & 49,95 & 38,21 & 26,46 \\
Fibra em detergente ácido (\%MS) & 36,43 & 30,55 & 23,63 & 17,55 & 11,24 \\
FDNcp (\%MS) & 66,83 & 56,20 & 45,36 & 34,83 & 23,75 \\
Celulose (\%MS) & 30,86 & 25,99 & 20,19 & 14,99 & 9,81 \\
Hemicelulose (\%MS) & 37,02 & 31,25 & 26,32 & 20,66 & 15,21 \\
Carboidratos totais (\%MS) & 82,99 & 76,39 & 76,77 & 76,73 & 76,64 \\
Carboidratos não fibrosos (\%MS) & 16,16 & 21,28 & 32,31 & 43,12 & 53,62 \\
Nutrientes digestíveis totais (\%MS) & 31,27 & 38,73 & 47,95 & 61,54 & 71,83 \\
NDT:PB & 3,28 & 2,40 & 2,97 & 3,78 & 4,39 \\
\hline
\end{tabular}

${ }^{1}$ Composição: Ca 7,5\%; P 3\%; Fe 16.500 ppm, Mn 9.750 ppm, Zn 35.000 ppm, I 1.000 ppm, Se 225 ppm, Co 1.000 ppm; ${ }^{2}$ Fibra em detergente neutro corrigida para cinzas e proteína; ${ }^{3}$ Relação Nutrientes digestíveis totais:proteína bruta.

Fonte: Elaboração dos autores.

Para analisar a digestibilidade dos nutrientes, a fibra em detergente neutro indigestível foi utilizada como indicador para estimar a produção de matéria seca fecal, conforme descrito por Casali et al. (2008). Quinzenalmente, foram coletadas amostras de fezes diretamente da ampola retal dos animais por três dias consecutivos, em três horários distintos (às 8:00 no primeiro dia, às 12:00 no segundo dia e às
16:00 no terceiro dia), obtendo-se nove amostras por animal. As amostras foram acondicionadas em sacos plásticos devidamente identificados e armazenadas em freezer $\mathrm{a}-10^{\circ} \mathrm{C}$ para formar, posteriormente, uma amostra composta/animal. As amostras de fezes, alimentos e sobras de alimentos foram pré-secas em estufa a $55^{\circ} \mathrm{C} \pm 5^{\circ} \mathrm{C}$, moídas, proporcionalmente sub amostradas e colocadas em sacos de náilon 
para incubação no rúmen de uma vaca Pardo Suíço, pesando em média $600 \mathrm{~kg}$ e alimentada com ração padrão constituída de $60 \%$ de volumoso e $40 \%$ de concentrado, por um período de 240 horas. Após este período, os sacos foram retirados e lavados em água corrente até apresentarem-se totalmente claros. Posteriormente, foram acondicionados em aparelho determinador de fibra, no qual foi utilizada solução de detergente neutro para extração dos componentes solúveis a $100^{\circ} \mathrm{C}$ por uma hora. Em seguida, foram lavados com água destilada quente $\left(>90^{\circ} \mathrm{C}\right)$ para total remoção do detergente e depois lavados com acetona, secos em estufa a $55 \pm 5^{\circ} \mathrm{C}$ por 24 horas e, finalmente, colocados em estufa a $105 \pm 5^{\circ} \mathrm{C}$ por uma hora, sendo, posteriormente, pesados.

$\mathrm{O}$ teor de NDT foi calculado utilizando a seguinte fórmula: $\mathrm{NDT}=\mathrm{PBd}+\mathrm{CNFd}+$ FDNcpd + (EEd x 2,25); sendo PBd, CNFd, FDNcpd e EEd correspondentes a: proteína bruta digestível, carboidratos não fibrosos digestíveis, fibra em detergente neutro corrigida para cinza e proteína digestível e extrato etéreo digestível, respectivamente, sendo o extrato etéreo multiplicado por 2,25 devido esta fração conter, aproximadamente, o dobro de energia do que as demais (WEISS, 1999).

Os valores de EM das dietas foram calculados com base no NDT (calculado a partir do ensaio de digestibilidade), considerando que $1 \mathrm{~kg}$ de NDT equivale a 4,409 Mcal de energia digestível (ED) e que a EM corresponde a $82 \%$ da $E D$, conforme o NRC (2000).

Ao final do período experimental, as amostras compostas de sobras, das dietas e fezes de cada animal e as amostras de feno e concentrado foram descongeladas, homogeneizadas separadamente, pré-secas em estufa a $55^{\circ} \mathrm{C} \pm 5^{\circ} \mathrm{C}$ por 72 horas e processadas em moinho com peneira de malha de $1 \mathrm{~mm}$, sendo então analisadas quanto aos teores de matéria seca (MS), matéria mineral (MM), proteína bruta $(\mathrm{PB})$ e extrato etéreo $(\mathrm{EE})$, seguindo os protocolos padrões da AOAC (1990); fibra insolúvel em detergente neutro (FDN) e ácido (FDA), celulose, hemicelulose e lignina, conforme Van Soest, Robertson e Lewis (1991). O teor de carboidratos totais (CT) foi calculado conforme Sniffen et al. (1992), onde: CT $(\%)=100-(\% \mathrm{~PB}+$ $\% \mathrm{EE}+\% \mathrm{MM})$. O teor de carboidratos não fibrosos (CNF) foi calculado conforme Weiss (1999), onde: $\mathrm{CNF}(\%)=100-(\% \mathrm{FDNcp}+\% \mathrm{~PB}+\% \mathrm{EE}+$ $\% \mathrm{MM}$ ). Para os concentrados, devido à presença de ureia em sua constituição, o teor de CNF foi calculado conforme Hall (2000), onde: $\mathrm{CNF}=100$ $-[(\% \mathrm{~PB}-\% \mathrm{PBderivado}$ da ureia $+\%$ da ureia $)+$ $\%$ FDNcp $+\%$ EE $+\% \mathrm{MM}]$.

Os animais foram pesados semanalmente para o acompanhamento do ganho de peso corporal e quando os animais de um dos tratamentos atingiram PC médio de $28 \mathrm{~kg}$, todos os 30 animais foram abatidos. Antes do abate, os animais foram pesados, submetidos a jejum de sólidos e líquidos por 18 horas e novamente pesados para obtenção do peso corporal no jejum (PCj). Após insensibilização por atordoamento, suspendeu-se o animal e através de um corte na veia jugular e artéria carótida, o sangue foi coletado, procedendo-se a esfola e evisceração. O trato gastrintestinal (TGI) foi separado, pesado cheio e, em seguida, esvaziado, lavado e após o escorrimento da água foi novamente pesado para que juntamente com o peso dos órgãos e demais componentes do corpo (carcaça, cabeça, patas, sangue e couro) fossem determinados o PCVZ. Logo, o PCVZ consiste na diferença entre PCj e o conteúdo do TGI, da vesícula biliar e da bexiga.

Todos os órgãos (sistema reprodutor, língua + traqueia + esôfago + pulmão + diafragma, fígado, coração, rins, baço, bexiga, vesícula biliar, rúmen + retículo, omaso, abomaso, intestino delgado e grosso, gordura omental, perirrenal, mesentérica e do coração) mais a cabeça, patas, sangue e couro foram pesados e armazenados em freezer a $-10^{\circ} \mathrm{C}$. $\mathrm{O}$ couro foi cortado em tiras e amostrado. A carcaça de cada animal foi resfriada por 24 horas a $5^{\circ} \mathrm{C}$ e, em seguida, pesada e cortada em serra de fita 
sobre a linha média dorsal a fim de utilizar a meia carcaça direita para determinação da composição química. A meia carcaça direita, órgãos + cabeça + patas + sangue e as amostras de couro de cada animal foram moídas separadamente em moedor industrial de carne, homogeneizadas, amostradas e armazenadas em freezer a $-10^{\circ} \mathrm{C}$. Posteriormente, as referidas amostras foram descongeladas em câmara fria a $4{ }^{\circ} \mathrm{C}$, pesadas em recipientes plásticos e desidratadas em liofilizador a -40 e $-60{ }^{\circ} \mathrm{C}$ por 48 horas. Terminado o processo de liofilização, as amostras foram pesadas novamente para obtenção do peso da amostra pré-seca. Por conseguinte, foram processadas em moinho de bola e, então, desengorduradas em sistema de refluxo com hexano em aparelho de Soxlet por 12 horas para obtenção do teor de gordura. O resíduo, após extração da gordura, foi colocado em estufa a $55 \pm 5^{\circ} \mathrm{C}$ por uma hora, processado em moinho de bola e, então, analisado para nitrogênio total pelo método de Kjeldahl. A multiplicação do teor de nitrogênio total pelo fator 6,25 permitiu a obtenção da proteína bruta das amostras. Para determinação do teor de matéria seca, uma parte de cada amostra foi colocada em placas de alumínio em estufa a $105^{\circ} \mathrm{C}$ por 24 horas.

As eficiências de utilização da energia metabolizável para mantença $(\mathrm{km})$ e ganho de peso (kf) foram estimadas de acordo com as equações descritas por Harris (1970) e pelo AFRC (1993). Segundo Harris (1970): km = ELm/EMm; kf = Elg/ $E M$, em que: ELm = exigência de energia líquida para mantença; EMm = exigência de energia metabolizável para mantença, estimada a partir do método interativo, onde a produção de calor é igual ao consumo de energia metabolizável; EM = concentração de energia metabolizável da dieta; Elg = concentração de energia líquida da dieta para ganho de peso, determinada a partir da razão entre a energia retida diária ( $\left.\mathrm{kcal} / \mathrm{kg} \mathrm{PCVZ}^{0,75}\right)$ e o consumo de matéria seca diário para ganho de peso (CMSg, g $\mathrm{MS} / \mathrm{kg} \mathrm{PCVZ}^{0,75}$ ). O CMSg foi determinado a partir da diferença entre o CMS diário ( $\mathrm{g} \mathrm{MS} / \mathrm{kg} \mathrm{PCVZ}{ }^{0,75}$ ) e o CMS para mantença diária (CMSm, g MS/kg
$\left.\mathrm{PCVZ}^{0,75}\right)$. O CMSm, por sua vez, foi determinado a partir da razão entre a EMm (kcal/kg PCVZ ${ }^{0,75} /$ dia) e a EM (Mcal/kg MS). Segundo AFRC (1993): km $=0,503+0,35 \mathrm{qm} ; \mathrm{kf}=0,006+0,78 \mathrm{qm} ; \mathrm{qm}=\mathrm{EM} /$ $\mathrm{EB}$, em que: $\mathrm{km}$ = eficiência de utilização da energia metabolizável para mantença; $\mathrm{kf}=$ eficiência de utilização da energia metabolizável para ganho de peso; qm = metabolizabilidade da dieta; $\mathrm{EM}=$ energia metabolizável da dieta e $\mathrm{EB}=$ energia bruta da dieta.

Para determinar as exigências de proteína metabolizável (PM) para mantença e ganho de peso foram adotados os valores de eficiência de utilização da PM para mantença $(\mathrm{kpm}=1)$ e ganho $(\mathrm{kpf}=$ $0,5)$, respectivamente, preconizados pelo NRC (2007). Para a conversão das exigências de PM total para proteína bruta $(\mathrm{PB})$ total foram adotadas as equações propostas por Valadares Filho e Oliveira (2010). Para a conversão das exigências de energia e proteína líquida para ganho de peso de corpo vazio (GPCVZ) em ganho de peso corporal (GPC), utilizou-se o fator 1,49 obtido da relação PC/PCVZ.

O CMS estimado foi obtido a partir de uma equação de regressão linear múltipla do CMS observado em função do ganho médio diário (GMD) e do peso corporal metabólico $\left(\mathrm{PC}^{0,75}\right)$ dos animais experimentais.

Para avaliar o modelo SRNS foram utilizados dados referentes a cada animal como PC e CMS, além de dados referentes à composição bromatológica das dietas e condições ambientais. As variáveis analisadas foram CMS e GMD. Desse modo, a avaliação do modelo, quanto à acurácia, foi realizada a partir do ajuste da equação de regressão linear simples dos valores observados (variável dependente) em função dos valores preditos (variável independente) e a avaliação, quanto à precisão, foi realizada mediante o uso do coeficiente de correlação de Pearson (r). Os parâmetros da equação foram testados sobre as seguintes hipóteses:

$$
\begin{array}{ll}
\mathrm{H}_{0}: \beta_{0}=0 & \mathrm{H}_{0}: \beta_{1}=1 \\
\mathrm{Ha}: \beta_{0} \neq 0 & \mathrm{Ha}: \beta_{1} \neq 1
\end{array}
$$


Para a não rejeição de ambas as hipóteses de nulidade, os valores preditos e observados são semelhantes, caso contrário, a tendência do modelo é subestimar ou superestimar a resposta do animal. $\mathrm{O}$ ajuste das equações de regressão linear foi realizado utilizando o PROC REG do SAS versão 9.0. O coeficiente de correlação de Pearson foi ajustado por meio do PROC CORR do SAS versão 9.0.

\section{Resultados e Discussão}

Considerando os valores de consumo de matéria seca (CMS, g/dia) em função do ganho médio diário (GMD) e do peso corporal metabólico
$\left(\mathrm{PC}^{0,75}\right)$ dos animais experimentais, obteve-se uma equação de regressão linear múltipla (CMS $=227,8674+1,3513 * \mathrm{GMD}-0,0008 * \mathrm{GMD}^{2}+$ $\left.25,5070 * \mathrm{PC}^{0,75}\right)$, cujos parâmetros desta equação podem ser observados na Tabela 3. Dessa maneira, considerando um animal com PC de $20 \mathrm{~kg}$ e GMD de $150 \mathrm{~g}$, o CMS estimado foi de 653,79 g/dia. Esse resultado foi similar àquele reportado pelo NRC (2007) de $650 \mathrm{~g} /$ dia para cordeiros de maturidade precoce e, aproximadamente, 18,28\%, 15,47\% e $19,29 \%$ inferior àqueles sugeridos pelo AFRC (1993), Cannas et al. (2004) e Cabral et al. (2008), respectivamente.

Tabela 3. Parâmetros da equação, erro padrão (EP), probabilidade (P-valor) e intervalo de confiança (IC95\%) dos parâmetros, coeficiente de determinação ajustado ( $\mathrm{R}^{2}$ ajustado) e coeficiente de variação (CV) do modelo geral da equação múltipla do consumo de matéria seca em função do ganho médio diário (GMD) e do peso corporal metabólico $\left(\mathrm{PC}^{0,75}\right)$ de cordeiros Santa Inês.

\begin{tabular}{lcccccc}
\hline Variáveis & Parâmetros da equação & EP & P-valor & IC95\% & $\mathrm{R}^{2}$ ajustado & CV (\%) \\
\hline Intercepto & 227,8674 & 202,500 & 0,271 & 455,735 & 0,55 & 15,80 \\
GMD & 1,3513 & 0,913 & 0,151 & 2,703 & - & - \\
$\mathrm{GMD}^{2}$ & $-0,0008$ & 0,003 & 0,809 & $-0,002$ & - & - \\
PC $^{0,75}$ & 25,5070 & 27,139 & 0,356 & 51,014 & - & - \\
\hline
\end{tabular}

Fonte: Elaboração dos autores.

Observou-se que a metabolizabilidade da dieta (qm) aumentou de 0,26 para 0,60 com a elevação nos níveis de EM de 1,13 para 2,60 Mcal/kg MS (Tabela 4). A partir da equação de regressão $\log \mathrm{PCl}_{\text {(kcal } /}$ $\mathrm{kg} \mathrm{PCVZ}^{0,75}$ /dia) $=1,7154+0,0023 *$ CEM, estimou-se o requerimento de energia líquida e metabolizável para mantença (ELm, EMm). Extrapolando a referida equação para o nível zero de CEM, obtevese o valor da ELm de 51,928 kcal/kg $\mathrm{PCVZ}^{0,75} / \mathrm{dia}$, conforme Lofgreen e Garrett (1968). Aplicando o método interativo na equação supracitada, obtevese o valor da EMm de 78,53 kcal $/ \mathrm{kg} \mathrm{PCVZ}^{0,75} / \mathrm{dia}$, que corresponde ao ponto de equilíbrio no qual a $\mathrm{PCl}$ é igual ao CEM, conforme metodologia descrita por Garrett (1980). Galvani et al. (2008), adotando a mesma metodologia, encontraram requerimento de $\mathrm{EMm}$ de $91 \mathrm{kcal} / \mathrm{kg} \mathrm{PC}^{0,75} /$ dia para cordeiros
11/16 Texel × 5/16 Ile de France. Dessa forma, a eficiência de utilização da energia metabolizável para mantença $(\mathrm{km})$, determinada a partir da relação entre a ELm e a EMm conforme equação descrita por Harris (1970), foi de 0,66. Esse resultado foi similar àqueles reportados por Cabral et al. (2008) de 0,66 e Galvani et al. (2008) de 0,64. Aplicando o valor médio da qm, observado neste estudo, na equação $\mathrm{km}=0,503+0,35 \mathrm{qm}$ proposta pelo AFRC (1993), onde qm = EM da dieta dividida pela energia bruta da dieta, obteve-se o valor de $\mathrm{km}$ igual a 0,65, similar ao valor obtido segundo a equação de Harris (1970). Esse resultado foi similar àquele relatado por Gonzaga Neto et al. (2005) para cordeiros Morada Nova e por Silva et al. (2003) para cordeiros Santa Inês, no qual o valor médio de $\mathrm{km}$ foi de 0,67 . Dessa forma, a adoção do valor 
de $\mathrm{km}$ estimado a partir da equação proposta pelo AFRC (1993) resulta em obtenção adequada do requerimento de EMm. Regadas Filho et al. (2011) também obtiveram valores similares para ambas as equações $(\mathrm{km}=0,70)$.

Tabela 4. Energia bruta (EB), Nutrientes digestíveis totais (NDT), consumo de matéria seca para mantença e ganho de peso (CMSm, CMSg), concentração de energia líquida na dieta para ganho de peso (Elg), metabolizabilidade da dieta (qm) e eficiências de utilização da energia metabolizável para mantença $(\mathrm{km})$ e ganho de peso (kf) de cordeiros Santa Inês.

\begin{tabular}{|c|c|c|c|c|c|}
\hline \multirow{2}{*}{ Variáveis } & \multicolumn{5}{|c|}{ Concentração de EM (Mcal/kg MS) } \\
\hline & 1,13 & 1,40 & 1,73 & 2,22 & 2,60 \\
\hline Energia bruta (EB) (Mcal/kg MS) & 4,35 & 4,35 & 4,33 & 4,29 & 4,30 \\
\hline Nutrientes digestíveis totais (NDT) (\%) & 31,27 & 38,73 & 47,95 & 61,54 & 71,83 \\
\hline CMS (g/kg PCVZ ${ }^{0,75}$ dia $)$ & 75,66 & 101,71 & 87,94 & 100,79 & 98,39 \\
\hline CMSm (g/kg PCVZ & 69,50 & 56,09 & 45,39 & 35,37 & 30,20 \\
\hline $\mathrm{CMSg}\left(\mathrm{g} / \mathrm{kg} \mathrm{PCVZ}{ }^{0,75} / \mathrm{dia}\right)$ & 6,17 & 45,61 & 42,55 & 65,42 & 68,19 \\
\hline Elg (Kcal) & 1,05 & 0,40 & 0,76 & 0,85 & 0,91 \\
\hline $\mathrm{qm}$ & 0,26 & 0,32 & 0,40 & 0,52 & 0,60 \\
\hline $\mathrm{km}^{1}$ & 0,66 & 0,66 & 0,66 & 0,66 & 0,66 \\
\hline $\mathrm{kf}^{1}$ & 0,93 & 0,29 & 0,44 & 0,38 & 0,35 \\
\hline $\mathrm{km}^{2}$ & 0,59 & 0,62 & 0,64 & 0,68 & 0,71 \\
\hline $\mathrm{kf}^{2}$ & 0,21 & 0,26 & 0,32 & 0,41 & 0,48 \\
\hline
\end{tabular}

${ }^{1}$ Calculado conforme Harris (1970); ${ }^{2}$ Calculado conforme AFRC (1993).

Fonte: Elaboração dos autores.

A eficiência de utilização da energia metabolizável para ganho de peso (kf), determinada a partir da relação entre a Elg e a EM da dieta conforme metodologia descrita por Harris (1970) decresceu de 0,44 para 0,35 com o acréscimo na concentração de EM da dieta de 1,73 para 2,60 Mcal/ $\mathrm{kg}$ MS. Comportamento inverso foi observado neste estudo utilizando a equação $\mathrm{kf}=0,006+0,78 \mathrm{qm}$ proposta pelo AFRC (1993), uma vez que, kf está em função de qm e, por essa razão, tende a aumentar com o acréscimo de qm. Salienta-se que, o aumento na inclusão de concentrado na dieta eleva o valor de qm resultando em redução no requerimento de EM. Comportamento semelhante foi observado por Regadas Filho et al. (2011) para os valores de kf estimados segundo Harris (1970) e AFRC (1993). O valor médio de $\mathrm{kf}$ estimado segundo o AFRC (1993) de 0,33 foi inferior ao valor médio de kf estimado segundo Harris (1970), de 0,48, indicando que a adoção do primeiro valor resulta em superestimação do requerimento de EMg.
Gonzaga Neto et al. (2005), encontraram valor médio de $\mathrm{kf}$ de 0,38 , estimado segundo o AFRC (1993). O valor médio de kf de 0,48, ligeiramente superior a outros estudos, provavelmente foi devido ao rápido crescimento dos animais, o que implicou também em menor requerimento de EMg quando comparado a outras raças. Além disso, segundo Garrett (1980), a eficiência de utilização da EM está diretamente relacionado à composição do ganho, sendo maior para deposição de gordura e menor para deposição de proteína, reafirmando a resposta observada neste estudo, uma vez que maior conteúdo de gordura foi constatado no corpo vazio nos animais experimentais. Esse resultado foi similar aquele observado por Galvani et al. (2008) de 0,47 e superior aquele relatado por Regadas Filho et al. (2011), de 0,43.

Os requerimentos totais de energia e proteína foram determinados a partir do método fatorial, que consiste no fracionamento dos requerimentos nutricionais líquidos, ou seja, os requerimentos 
para mantença, ganho de peso, gestação, lactação e produção de lã são determinados separadamente e, então, somados (RESENDE et al., 2008). Para converter as exigências de ELm para EMm e ELg para $\mathrm{EMg}$, estas foram divididas pelos valores médios de $\mathrm{km}$ e kf de 0,66 e 0,48, respectivamente
(Tabela 5). Como esperado, a exigência de NDT aumentou com o acréscimo no PC e no GMD dos animais, uma vez que, as exigências energéticas apresentaram o mesmo comportamento, o qual foi atribuído ao aumento na deposição de gordura no corpo vazio dos animais com o acréscimo no PC.

Tabela 5. Exigências diárias de energia de cordeiros Santa Inês.

\begin{tabular}{|c|c|c|c|c|c|c|c|c|c|}
\hline $\mathrm{PCVZ}^{1}$ & GMD & $\mathrm{CMS}^{2}$ & $\mathrm{ELm}^{3}$ & ELg & ELt & $\mathrm{EMm}^{4}$ & $\mathrm{EMg}^{5}$ & EMt & NDT \\
\hline \multicolumn{10}{|c|}{$15 \mathrm{~kg}$ PC } \\
\hline 8,34 & 100 & 549,47 & 0,255 & 0,165 & 0,420 & 0,386 & 0,344 & 0,730 & 0,202 \\
\hline 8,34 & 150 & 607,10 & 0,255 & 0,248 & 0,502 & 0,386 & 0,516 & 0,902 & 0,249 \\
\hline 8,34 & 200 & 660,77 & 0,255 & 0,330 & 0,585 & 0,386 & 0,688 & 1,074 & 0,297 \\
\hline 8,34 & 250 & 710,46 & 0,255 & 0,413 & 0,668 & 0,386 & 0,860 & 1,246 & 0,345 \\
\hline \multicolumn{10}{|c|}{$20 \mathrm{~kg}$ PC } \\
\hline 12,77 & 100 & 596,28 & 0,351 & 0,183 & 0,534 & 0,531 & 0,381 & 0,912 & 0,252 \\
\hline 12,77 & 150 & 653,92 & 0,351 & 0,274 & 0,625 & 0,531 & 0,571 & 1,103 & 0,305 \\
\hline 12,77 & 200 & 707,58 & 0,351 & 0,366 & 0,716 & 0,531 & 0,762 & 1,293 & 0,358 \\
\hline 12,77 & 250 & 757,28 & 0,351 & 0,457 & 0,808 & 0,531 & 0,952 & 1,484 & 0,410 \\
\hline \multicolumn{10}{|c|}{$25 \mathrm{~kg}$ PC } \\
\hline 17,19 & 100 & 640,23 & 0,438 & 0,196 & 0,635 & 0,664 & 0,409 & 1,073 & 0,297 \\
\hline 17,19 & 150 & 697,87 & 0,438 & 0,295 & 0,733 & 0,664 & 0,614 & 1,278 & 0,354 \\
\hline 17,19 & 200 & 751,53 & 0,438 & 0,393 & 0,831 & 0,664 & 0,818 & 1,483 & 0,410 \\
\hline 17,19 & 250 & 801,23 & 0,438 & 0,491 & 0,929 & 0,664 & 1,023 & 1,687 & 0,467 \\
\hline \multicolumn{10}{|c|}{$30 \mathrm{~kg}$ PC } \\
\hline 21,62 & 100 & 682,02 & 0,521 & 0,208 & 0,728 & 0,789 & 0,432 & 1,221 & 0,338 \\
\hline 21,62 & 150 & 739,65 & 0,521 & 0,311 & 0,832 & 0,789 & 0,649 & 1,437 & 0,398 \\
\hline 21,62 & 200 & 793,32 & 0,521 & 0,415 & 0,936 & 0,789 & 0,865 & 1,654 & 0,457 \\
\hline 21,62 & 250 & 843,01 & 0,521 & 0,519 & 1,039 & 0,789 & 1,081 & 1,870 & 0,517 \\
\hline
\end{tabular}

$\mathrm{PC}=$ Peso corporal $(\mathrm{kg}) ; \mathrm{PCVZ}=$ Peso de corpo vazio $(\mathrm{kg}) ; \mathrm{GMD}=$ Ganho médio diário (g/dia); CMS = Consumo de matéria seca (g/dia); ELm = Energia líquida para mantença $(\mathrm{Mcal} /$ dia); ELg = Energia líquida para ganho de peso $(\mathrm{Mcal} /$ dia $) ;$ ELt = Energia líquida total (Mcal/dia); EMm = Energia metabolizável para mantença (Mcal/dia); EMg = energia metabolizável para ganho de peso $(\mathrm{Mcal} / \mathrm{dia}) ; \mathrm{EMt}=$ Energia metabolizável total $(\mathrm{Mcal} / \mathrm{dia}) ; \mathrm{NDT}=$ Nutriente digestíveis totais $(\mathrm{kg} / \mathrm{dia})$.

${ }^{1} \mathrm{PCVZ}=-4,932+0,885 * \mathrm{PC} ;{ }^{2} \mathrm{CMS}=227,8674+1,3513 * \mathrm{GMD}-0,0008 * \mathrm{GMD}^{2}+25,5070 * \mathrm{PC}, 75 ;{ }^{3} \mathrm{ELm}=51,928 \mathrm{kcal} / \mathrm{kg}$ $\mathrm{PCVZ}^{0,75} / \mathrm{dia} ;{ }^{4} \mathrm{~km}=0,66 ;{ }^{5} \mathrm{kf}=0,48$.

Fonte: Elaboração dos autores.

Para converter as exigências de PLm para PMm e PLg para PMg, estas foram divididas pelos valores de kpm e kpf de 1,0 e 0,5, respectivamente, conforme NRC (2007) (Tabela 6). Para converter a PMt em $\mathrm{PB}$, foram consideradas as seguintes equações: $\operatorname{PBmic}_{(\mathrm{g} / \mathrm{dia})}=120 * \mathrm{NDT}_{(\mathrm{kg})} ; \mathrm{PDR}_{(\mathrm{g} / \mathrm{dia})}=\mathrm{PBmic} / 0,85$; $\mathrm{PNDR}_{(\mathrm{g} / \mathrm{dia})}=\left(\mathrm{PMt}-\left(\mathrm{PBmic}^{*} 0,64\right)\right) / 0,70 ; \mathrm{PB}_{(\mathrm{g} / \mathrm{dia})}$ $=\mathrm{PDR}+\mathrm{PNDR}$, conforme descrito por Valadares Filho e Oliveira (2010). A exigência de PMt aumentou com o acréscimo no PC e no GMD dos animais devido ao aumento na exigência de PLm com o acréscimo no PC e o aumento na exigência de PLg com o acréscimo no GMD dos animais. Os resultados foram similares àqueles observados por Regadas Filho et al. (2011) para a mesma faixa de PC e GMD. Para cordeiros com PC variando de 15 a $30 \mathrm{~kg}$ e GMD de $100 \mathrm{~g}$, esses pesquisadores encontraram requerimentos de PMt variando de 32,02 a $39,40 \mathrm{~g} / \mathrm{dia}$, respectivamente, enquanto neste estudo os valores variaram de 34,25 a 37,45 
g/dia. O aumento na exigência de PMt com o acréscimo do PC e do GMD também foram relatados por AFRC (1993), Pires et al. (2000), Gonzaga Neto et al. (2005) e NRC (2007), no entanto, os resultados foram, em média, 43,52\%, 38,06\%, $38,64 \%$ e $23,85 \%$, respectivamente, superiores. Isso é justificado, possivelmente, pelas variações nas condições ambientais e/ou raciais.

Tabela 6. Exigências diárias de proteína de cordeiros Santa Inês.

\begin{tabular}{|c|c|c|c|c|c|c|c|c|c|c|c|}
\hline $\mathrm{PCVZ}^{1}$ & GMD & $\mathrm{PLm}^{2}$ & PLg & PLt & $\mathrm{PMm}^{3}$ & $\mathrm{PMg}^{4}$ & $\mathrm{PMt}$ & PBmic. & PDR & PNDR & PB \\
\hline \multicolumn{12}{|c|}{$15 \mathrm{~kg}$ PC } \\
\hline 8,34 & 100 & 10,21 & 12,02 & 22,23 & 10,21 & 24,04 & 34,25 & 24,23 & 28,51 & 26,78 & 55,28 \\
\hline 8,34 & 150 & 10,21 & 18,03 & 28,24 & 10,21 & 36,06 & 46,27 & 29,94 & 35,22 & 38,73 & 73,95 \\
\hline 8,34 & 200 & 10,21 & 24,04 & 34,25 & 10,21 & 48,08 & 58,29 & 35,64 & 41,94 & 50,68 & 92,62 \\
\hline 8,34 & 250 & 10,21 & 30,05 & 40,26 & 10,21 & 60,10 & 70,31 & 41,35 & 48,65 & 62,63 & 111,28 \\
\hline \multicolumn{12}{|c|}{$20 \mathrm{~kg} P C$} \\
\hline 12,77 & 100 & 12,67 & 11,14 & 23,81 & 12,67 & 22,28 & 34,95 & 30,28 & 35,63 & 22,24 & 57,87 \\
\hline 12,77 & 150 & 12,67 & 16,71 & 29,38 & 12,67 & 33,41 & 46,09 & 36,60 & 43,06 & 32,37 & 75,44 \\
\hline 12,77 & 200 & 12,67 & 22,28 & 34,95 & 12,67 & 44,55 & 57,22 & 42,93 & 50,50 & 42,50 & 93,00 \\
\hline 12,77 & 250 & 12,67 & 27,84 & 40,52 & 12,67 & 55,69 & 68,36 & 49,25 & 57,94 & 52,64 & 110,57 \\
\hline \multicolumn{12}{|c|}{$25 \mathrm{~kg}$ PC } \\
\hline 17,19 & 100 & 14,98 & 10,56 & 25,54 & 14,98 & 21,12 & 36,10 & 35,63 & 41,92 & 19,00 & 60,92 \\
\hline 17,19 & 150 & 14,98 & 15,84 & 30,82 & 14,98 & 31,68 & 46,66 & 42,42 & 49,91 & 27,88 & 77,78 \\
\hline 17,19 & 200 & 14,98 & 21,12 & 36,10 & 14,98 & 42,24 & 57,22 & 49,21 & 57,90 & 36,75 & 94,65 \\
\hline 17,19 & 250 & 14,98 & 26,40 & 41,38 & 14,98 & 52,80 & 67,78 & 56,00 & 65,89 & 45,63 & 111,52 \\
\hline \multicolumn{12}{|c|}{$30 \mathrm{~kg}$ PC } \\
\hline 21,62 & 100 & 17,18 & 10,14 & 27,31 & 17,18 & 20,27 & 37,45 & 40,53 & 47,69 & 16,44 & 64,13 \\
\hline 21,62 & 150 & 17,18 & 15,20 & 32,38 & 17,18 & 30,41 & 47,59 & 47,71 & 56,13 & 24,36 & 80,49 \\
\hline 21,62 & 200 & 17,18 & 20,27 & 37,45 & 17,18 & 40,55 & 57,72 & 54,88 & 64,57 & 32,28 & 96,85 \\
\hline 21,62 & 250 & 17,18 & 25,34 & 42,52 & 17,18 & 50,68 & 67,86 & 62,06 & 73,01 & 40,20 & 113,21 \\
\hline
\end{tabular}

$\mathrm{PC}=$ Peso corporal $(\mathrm{kg}) ; \mathrm{PCVZ}=$ Peso de corpo vazio $(\mathrm{kg}) ; \mathrm{GMD}=$ Ganho médio diário $(\mathrm{g} /$ dia $)$; PLm = Proteína líquida para mantença $(\mathrm{g} / \mathrm{dia}) ; \mathrm{PLg}=$ Proteína líquida para ganho de peso $(\mathrm{g} / \mathrm{dia}) ; \mathrm{PLt}=$ Proteína líquida total $(\mathrm{g} / \mathrm{dia}) ;$ PMm $=$ Proteína metabolizável para mantença $(\mathrm{g} /$ dia); PMg = Proteína metabolizável para ganho de peso (g/dia); PMt = Proteína metabolizável total (g/dia); PBmic = Proteína microbiana (g/dia); PDR = Proteína degradável no rúmen (g/dia); PNDR = Proteína não degradável no rúmen $(\mathrm{g} / \mathrm{dia}) ; \mathrm{PB}=$ Proteína bruta $(\mathrm{g} / \mathrm{dia})$.

${ }^{1} \mathrm{PCVZ}=-4,932+0,885 * \mathrm{PC} ;{ }^{2} \mathrm{PLm}=1,34 \mathrm{~g} / \mathrm{kg} \mathrm{PC}, 75 / \mathrm{dia} ;{ }^{3} \mathrm{kpm}=1,0(\mathrm{NRC}, 2007) ;{ }^{4} \mathrm{kpf}=0,5(\mathrm{NRC}, 2007)$.

Fonte: Elaboração dos autores.

Observou-se que o modelo SRNS subestimou o CMS em cordeiros Santa Inês em 6,2\%, uma vez que, a hipótese de nulidade foi rejeitada $(\mathrm{P}<0,001)$ (Figura 1). A equação ajustada foi: $\mathrm{Y}=-179,69+$ $1,3766 * X\left(R^{2}=0,4586 ; C V=17,72\right) . O$ coeficiente de correlação de Pearson foi relativamente alto $(\mathrm{r}$ $=0,68 ; \mathrm{P}<0,001)$. Esse comportamento discorda daquele relatado por Regadas Filho et al. (2011), no qual o modelo SRNS foi sensível em predizer o CMS em cordeiros Santa Inês.

Embora o coeficiente de correlação de Pearson (r) tenha sido elevado $(\mathrm{r}=0,96 ; \mathrm{P}<0,001)$, observou-se que o modelo SRNS subestimou o GMD em cordeiros Santa Inês em 24,6\%, uma vez que, a hipótese de nulidade foi rejeitada $(\mathrm{P}<$ 0,001) (Figura 2). A equação ajustada foi: $\mathrm{Y}=$ $46,215+0,9209 * \mathrm{X}\left(\mathrm{R}^{2}=0,9286 ; \mathrm{CV}=11,42\right)$. Esse comportamento discorda daquele relatado por Regadas Filho et al. (2011), no qual o modelo SRNS superestimou o GMD em cordeiros Santa Inês em 5,18\%. Segundo Galvani et al. (2008), essas divergências entre o GMD predito pelo modelo e o GMD observado pode ser em parte devido as variações nas exigências energéticas. 
Figura 1. Relação entre o consumo de matéria seca (CMS) observado e o CMS predito pelo modelo SRNS em cordeiros Santa Inês.

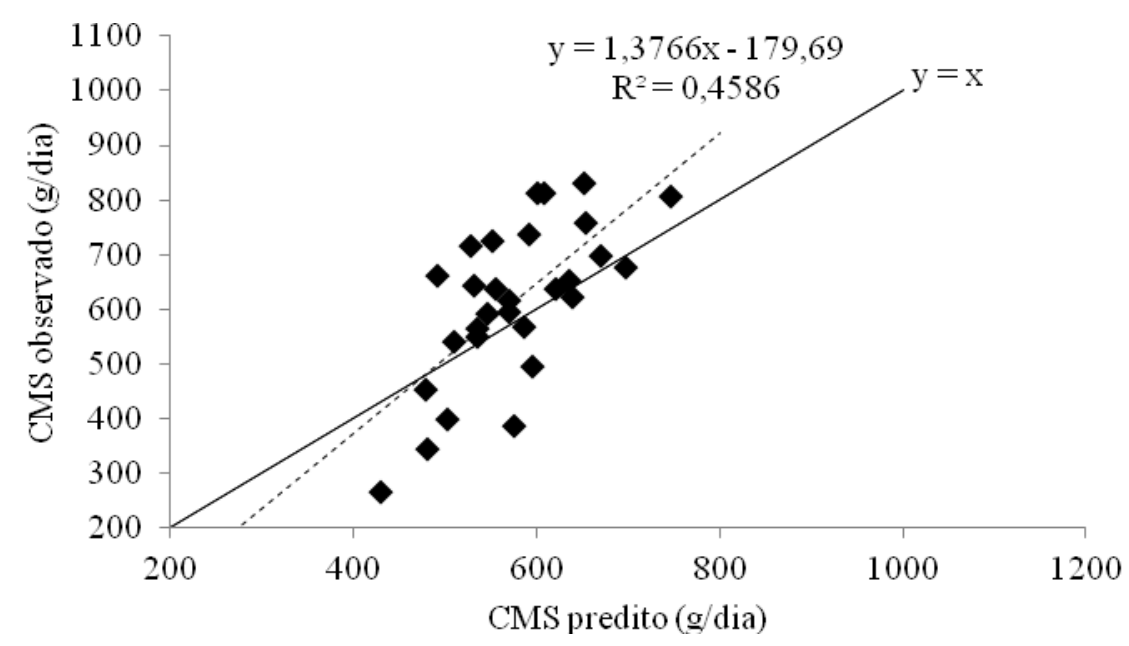

Fonte: Elaboração dos autores.

Figura 2. Relação entre o ganho médio diário (GMD) observado e o GMD predito pelo modelo SRNS em cordeiros Santa Inês

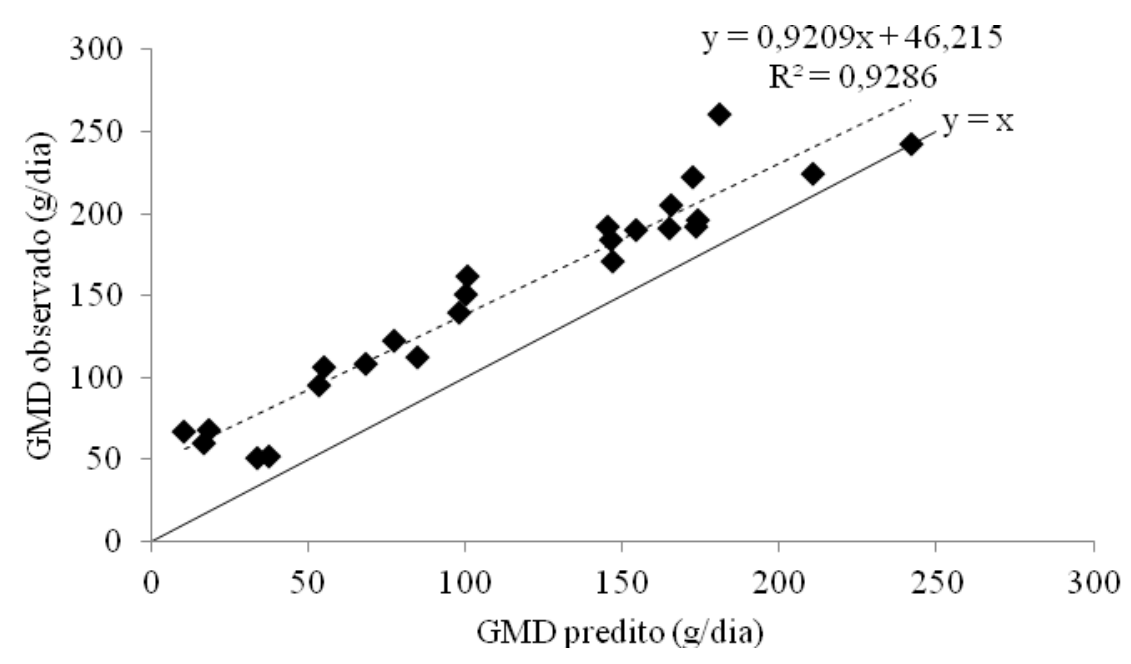

Fonte: Elaboração dos autores.

\section{Conclusões}

As eficiências de utilização da energia metabolizável para mantença $(\mathrm{km})$ e ganho de peso (kf) em cordeiros Santa Inês com peso corporal de
15 a $30 \mathrm{~kg}$ são de $66 \%$ e $48 \%$, respectivamente, valores estes consistentes com aqueles observados em diversos estudos com cordeiros criados nos trópicos. 
As exigências dietéticas de nutrientes digestíveis totais e proteína metabolizável total para diferentes pesos corporais e ganhos médios diários são, aproximadamente, $42 \%$ e $24 \%$, respectivamente, inferiores àquelas sugeridas pelo sistema americano de avaliação de alimentos e requerimentos nutricionais de pequenos ruminantes.

O modelo Small Ruminant Nutrition System é sensível para predizer o consumo de matéria seca em cordeiros Santa Inês, mas para ganho médio diário, mais estudos são necessários, uma vez que, o modelo subestima a resposta dos animais.

\section{Agradecimentos}

Ao CNPq e Banco do Nordeste do Brasil pelo suporte financeiro para a realização desse trabalho de pesquisa.

\section{Referências}

AGRICULTURAL AND FOOD RESEARCH COUNCIL - AFRC. Energy and protein requirements of ruminants. Wallingford: Commonwealth Agricultural Bureaux International, 1993. 159 p.

ASSOCIATION OF OFFICIAL ANALYTICAL CHEMISTS - AOAC. Official methods of analysis. $15^{\text {td }}$ ed. Virginia: Arlington, 1990. 1298 p.

CABRAL, L. S.; NEVES, E. M. O.; ZERVOUDAKIS, J. T.; ABREU, J. G.; RODRIGUES, R. C.; SOUZA, A. L.; OLIVEIRA, I. S. Estimativas dos requisitos nutricionais de ovinos em condições brasileiras. Revista Brasileira de Saúde e Produção Animal, Salvador, v. 9, n. 3, p. 529542, 2008.

CANNAS, A.; TEDESCHI, L. O.; FOX, D. G.; PELL, A. N.; VAN SOEST, P. J. A mechanistic model for predicting the nutrient requirements and feed biological values for sheep. Journal of Animal Science, Champaign, v. 82, n. 1, p. 149-169, 2004.

CARVALHO, S.; PIRES, C. C.; SILVA, J. H. Composição corporal e exigências líquidas de proteína para ganho de peso de cordeiros. Revista Brasileira de Zootecnia, Viçosa, v. 29, n. 8, p. 2325-2331, 2000.

CASALI, A. O.; DETMANN, E.; VALADARES FILHO, S. C.; PEREIRA, J. C.; HENRIQUES, L. T.; FREITAS, S. G.; PAULINO, M. F. Influência do tempo de incubação e do tamanho de partículas sobre os teores de compostos indigestíveis em alimentos e fezes bovinas obtidos por procedimentos in situ. Revista Brasileira de Zootecnia, Viçosa, v. 37, n. 2, p. 335-342, 2008.

GALVANI, D. B.; PIRES, C. C.; KOZLOSKI, G. V.; WOMMER, T. P. Energy requirements of texel crossbred lambs. Journal of Animal Science, Champaign, v. 86, n. 12, p. 3480-3490, 2008.

GARRETT, W. N. Factors influencing energetic efficiency of beef production. Journal of Animal Science, Champaign, v. 51, n. 6, p. 1434-1440, 1980.

GONZAGA NETO, S.; SILVA SOBRINHO, A. G.; RESENDE, K. T.; ZEOLA, N. M. B. L.; SILVA, A. M. A.; MARQUES, C. A. T.; LEÃO, A. G. Composição corporal e exigências nutricionais de proteína e energia para cordeiros Morada Nova. Revista Brasileira de Zootecnia, Viçosa, v. 34, n. 6, p. 2446-2456, 2005.

HALL, M. B. Calculation of non-structural carbohydrate content of feeds that contain non-protein nitrogen. Gainesville: University of Florida, 2000. p. A25-A32. (Bulletin, 339).

HARRIS, L. F. Nutrition research techniques for domestics and wild animals. Utah: Logan, 1970. 240 p. v. 1.

LOFGREEN, G. P.; GARRETT, W. N. A system for expressing net energy requirements and feed values for growing and finishing beef cattle. Journal of Animal Science, Champaign, v. 27, n. 3, p. 793-806, 1968.

NATIONAL RESEARCH COUNCIL - NRC. Nutrient requirements of beef cattle. 7. ed. Washington, D. C.: National Academy Press, 2000. 242 p.

Nutrient requirements of small ruminants. Washington, D. C.: National Academy Press, 2007. 384 p.

OLIVEIRA, A. N.; PÉREZ, J. R. O.; CARVALHO, P. A.; PAULA, O. J.; BAIÃO, E. A. M. Composição corporal e exigências líquidas em energia e proteína para ganho de cordeiros de quatro grupos genéticos. Ciência e Agrotecnologia, Lavras, v. 28, n. 5, p. 1169-1176, 2004.

PIRES, C. C.; SILVA, L. F.; BONNECARRÈRE SANCHEZ, L. M. Composição corporal e exigências nutricionais de energia e proteína para cordeiros em crescimento. Revista Brasileira de Zootecnia, Viçosa, v. 29, n. 3, p. 853-860, 2000.

REGADAS FILHO, J. G. L.; PEREIRA, E. S.; VILLARROEL, A. B. S.; PIMENTEL, P. G.; FONTENELE, R. M.; COSTA, M. R. G. F.; MAIA, I. S. G.; SOMBRA, W. A. Efficiency of metabolizable energy utilization for maintenance and gain and evaluation of 
small ruminant nutrition system model in Santa Ines sheep. Revista Brasileira de Zootecnia, Viçosa, v. 40, n. 11, p. 2558-2564, 2011.

RESENDE, K. T.; SILVA, H. G. O.; LIMA, L. D.; TEIXEIRA, I. A. M. A. Avaliação das exigências nutricionais de pequenos ruminantes pelos sistemas de alimentação recentemente publicados. Revista Brasileira de Zootecnia, Viçosa, v. 37, p. 161-177, 2008.

SILVA, A. M. A.; SILVA SOBRINHO, A. G.; TRINDADE, I. A. C. M.; RESENDE, K. T.; BAKKE, O. A. Net requirements of protein and energy for maintenance of wool and hair lambs in a tropical region. Small Ruminant Research, Amsterdam, v. 49, n. 2, p. 165-171, 2003.

SNIFFEN, C. J.; O'CONNOR, J. D.; VAN SOEST, P. J.; FOX, D. G.; RUSSELL, J. B. A net carbohydrate and protein system for evaluating cattle diets: carbohydrate and protein availability. Journal of Animal Science, Champaign, v. 70, n. 11, p. 3562-3577, 1992.
TEDESCHI, L. O.; CANNAS, A.; FOX, D. G. A nutrition mathematical model to account for dietary supply and requirements of energy and nutrients for domesticated small ruminants: the development and evaluation of the Small Ruminant Nutrition System. Revista Brasileira de Zootecnia, Viçosa, v. 37, p. 178-190, 2008.

VALADARES FILHO, S. C.; OLIVEIRA, A. S. Compostos nitrogenados na alimentação para novilhas leiteiras. In: PEREIRA, E. S.; PIMENTEL, P. G.; QUEIROZ, A. C.; MIZUBUTI, I. Y. Novilhas leiteiras. Fortaleza: Graphiti Gráfica e Editora Ltda, 2010. p. 333372.

VAN SOEST, P. J.; ROBERTSON, J. B.; LEWIS, B. A. Methods for dietary fiber, neutral detergent fiber, and nostarch polyssacharides in relation to animal nutrition. Journal of Dairy Science, Champaign, v. 74, n. 10, p. 3583-3597, 1991.

WEISS, W. P. Energy prediction equations for ruminant feeds. In: CORNELL NUTRITION CONFERENCE FOR FEED MANUFACTURERS, 61., 1999, Ithaca. Proceedings... Ithaca: Cornell University, 1999. p. 176185. 
